\title{
The mechanisms by which antidepressants may reduce coronary heart disease risk
}

\author{
Marc J. Mathews", Edward H. Mathews and Leon Liebenberg
}

\begin{abstract}
Background: Depression is known to increase the risk for coronary heart disease (CHD) likely through various pathogenetic actions. Understanding the links between depression and CHD and the effects of mediating these links may prove beneficial in CHD prevention.

Methods: An integrated model of CHD was used to elucidate pathogenetic pathways of importance between depression and CHD. Using biomarker relative risk data the pathogenetic effects are representable as measurable effects based on changes in biomarkers.

Results: A 'connection graph' presents interactions by illustrating the relationship between depression and the biomarkers of CHD. The use of selective serotonin reuptake inhibitors (SSRIs) is postulated to have potential to decrease CHD risk. Comparing the 'connection graph' of SSRI's to that of depression elucidates the possible actions through which risk reduction may occur.
\end{abstract}

Conclusions: The CHD effects of depression appear to be driven by increased inflammation and altered metabolism. These effects might be mediated with the use of SSRI's.

\section{Background}

Depression is one of several preventable causes of disability worldwide, with coronary heart disease (CHD) being the largest cause of disability [1]. In addition, CHD is also the largest cause of death globally [2].

There is an established link between these two disorders, where depression has been noted as a risk factor for CHD [3] and patients with established CHD have been found to have increased incidence of depression compared to controls [4]. Depressed CHD patients are significantly linked to increased mortality [5] and poor prognosis for further CHD events [6]. Depressed patients using antidepressants appear to be at a reduced risk for CHD. However, the mechanisms behind this reduced risk are not clear [7].

To gain more insight into associations between depression, antidepressants, and CHD an integrated model of CHD pathogenesis, health factors, biomarkers and pharmacotherapeutics would be beneficial [8]. We can then consider the effect of treatment of depression with antidepressants on the pathogenesis of CHD. This will help with

* Correspondence: mjmathews@rems2.com

CRCED Pretoria, North-West University, P.O. Box 11207, Silver Lakes 0054, South Africa insight as to how antidepressants might decrease CHD risk in the depressed.

\section{Methods}

Health factor integration with CHD

Our integrated model was developed and described in a previous article [9]. Briefly, a systematic review of the literature from after 1998 and including highly cited papers was conducted for CHD pathogenesis, health factors, biomarkers and pharmacotherapeutics. This research was combined to develop the integrated model of CHD [9].

The health factors in the integrated model were considered as lifestyle effects or comorbid health disorders which have been associated with statistically significant increases or decreases in CHD risk. The pharmaceuticals in the integrated model were those whose use has been associated with statistically significant decreases in CHD risk in primary or secondary prevention.

The biomarkers considered for the integrated model were mainly those whose measurement has been associated with statistically significant increases or decreases in 
CHD risk. However, some biomarker data was included where results have not been statistically significant as an emphasis of their lack of prediction ability.

The above components were combined to develop the integrated model [9] which will be used in this article to describe the interconnections of depression on the pathogenesis of CHD. We attempt to quantify the CHD effect of depression and antidepressants by the effect thereof on an array of biomarkers which represent increasing or decreasing CHD risk. The study dealt mainly with the primary prevention aspects as most of the data gathered for the effects of SSRI use on the biomarkers was from studies in patients without CHD.

\section{Statistical analysis}

It must be noted that some of the RR values in this article are presented in a manner which differs from convention [9]. The need for this comes as a result of the visual scaling of the traditional RR. Traditionally, if one plots an $R R=3$ and $R R=0.33$, respectively, the one does not 'look' three times worse and the other three times better than the normal $R R=1$. The reason is that the scales for the positive and negative effects are not numerically similar. A graph of 'good' and 'bad' RR can therefore be deceptive for the untrained person, e.g., a patient.

This article rather uses the method that the conventional $R R=3$ is three times worse than the normal $R R=1$. While the conventional $R R=0.33$ means that the patient's position is three times better than the normal $R R=1$. Thus, in summary: a conventional $R R=3$ is presented as per normal, as a 3 -fold increase in risk and a conventional $\mathrm{RR}=0.33$ is presented as a 3 -fold decrease in risk $(1 / 0.33=3)$.

\section{Results}

\section{Integrated model}

The integrated model in Fig. 1 schematically illustrates the complexity of CHD and shows all theoretical pathogenetic pathways between the health factors and CHD. The health factors that are described by the integrated model include both modifiable lifestyle effects and underlying comorbid disorders such as depression. A more detailed discussion of Fig. 1, relevant to depression, is given in next section.

The pathways (pathogenesis of CHD) within the integrated model can be tracked from where a chosen health factor influences the relevant tissue, to the end state of CHD. This will be conducted for depression in the following section of this study. The pathways presented in Fig. 1 are a visual representation of previously published knowledge. Salient serological biomarkers (shown in Fig. 1 as ) and pharmacotherapeutics (shown in Fig. 1 as $\vdash \square$ ) that act on the pathways are further indicated in Fig. 1.

\section{Pathogenetic effects of depression}

In order to appraise the CHD effects of depression, the relevant pathogenetic pathways need to be considered. While Fig. 1 also indicates other health factors, only the pathways activated by depression, presented in Fig. 1, are summarized in Table 1 . It is important to note that not all of the pathways will be relevant to every patient and that all the pathways may not be active simultaneously, or occur in the same patient.

Some of the pathological effects of depression on CHD are thought to be mediated by the over stimulation of the hypothalamic-pituitary-adrenocortical (HPA) axis [10]. Increased levels of corticotropin-releasing factor (CRF) and its stimulation of the production and release of adrenocorticotropic hormone (ACTH), mediates the activation of the HPA axis [11]. This can lead to increased plasma cortisol levels [12]. The overstimulation of the HPA axis may augment sympathoadrenal (SA) hyperactivity via central regulatory pathways, resulting in increased plasma catecholamines [13], such as norepinephrine, epinephrine and dopamine [14].

Chronic dysregulation of the HPA axis, such as in depression, can lead to chronically increased serum levels of cortisol [12], which can have negative effects on insulin and blood glucose levels [15]. The effect of cortisol on blood glucose is shown in the integrated model (Fig. 1) through pathway 7-27-48-14-blood glucose-55hyperglycaemia, with the possibility that over stimulation of the pathway could lead to the CHD hallmark of hyperglycaemia.

Further, abnormalities in blood glucose control and insulin sensitivity are seen in patients with major depressive disorder, even in individuals who are nonobese and not diabetic [16]. Some of these effects may be explained by the increased secretion of glucocorticoids, which oppose the effects of insulin and increases the turnover between stored energy, in the form of glycogen, triglycerides and protein, and freely available fuel for mitochondrial oxidation, in the form of glucose and free fatty acids [17]. This serves to increase blood glucose levels. Blood glucose levels can also be increased, by glucocorticoids, through an effect on hepatic gluconeogenesis and insulin secretion [15]. (Fig. 1, Pathway: 7-27-48-14-55-hyperglycaemia).

Pathways: 6-27-47 and 7-26-44 in the integrated model (Fig. 1) show how catecholamines and glucocorticoids inhibit insulin actions and thus contribute to insulin resistance $[18,19]$. Additionally, it is possible for insulin resistance to occur due to inhibition of the phosphatidylinositol 3-kinase (PI3K) insulin signaling pathway 
or the stimulation of the MAPK pathway [20]. (Fig. 1, Pathways: 7-27-48-14-54-69-72-14-55- hyperinsulinaemia).

Elevated glucocorticoids can increase the responsiveness to vasoconstrictors and reduce vasodilator production, noted by a reduction in nitric oxide $(\mathrm{NO})$ production or bioavailability, contributing to glucocorticoid induced hypertension [21]. (Fig. 1, Pathway: 7-27-48-14-53-57vasodilation).
Another possible mechanism underlying glucocorticoid induced hypertension is shown in the integrated model (Fig. 1) by pathway: 7-27-48-14-54-89-hypertension. This details how depression could lead to increased activity of the renin-angiotensin-aldosterone system, high leptin levels and concurrent leptin resistance [22]. Furthermore increased HPA axis activity can also increase oxidative stress along with decreased antioxidant defenses [23],

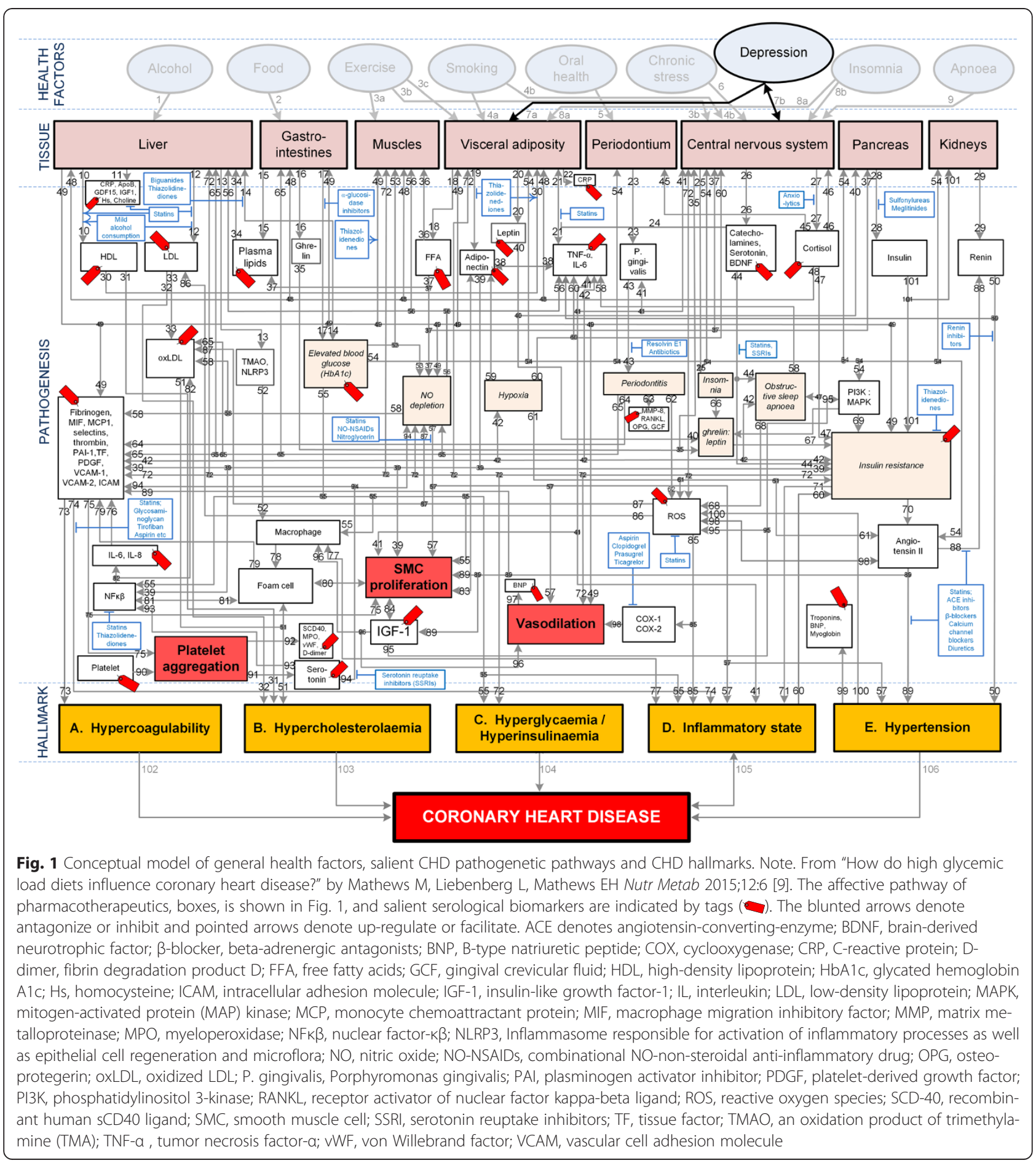


Table 1 Putative effects of depression and salient CHD pathogenetic pathways

\begin{tabular}{|c|c|}
\hline Pathways, and pathway numbers corresponding to those in Fig. 1 & Refs. \\
\hline a. 7-26- $\uparrow$ catecholamines $/ \downarrow$ serotonin/ $\downarrow$ BDNF-44- $\uparrow$ platelet factors-73- $\uparrow$ hypercoagulability & a. [95-97] \\
\hline b. 7-26- $\uparrow$ catecholamines $/ \downarrow$ serotonin/ $\downarrow$ BDNF-44- $\uparrow$ NO depletion-57- $\uparrow$ SMC proliferation & b. [95] \\
\hline c. 7-26- $\uparrow$ catecholamines $/ \downarrow$ serotonin/ $\downarrow$ BDNF-44- $\uparrow$ NO depletion-57- $\uparrow$ vasodilation & c. [95] \\
\hline $\begin{array}{l}\text { d. } 7-26-\uparrow \text { catecholamines } / \downarrow \text { serotonin } / \downarrow \text { BDNF-44- } \uparrow \text { insulin resistance-70- } \uparrow \text { angiotensin II-89- } \uparrow \text { hypertension-100- } \uparrow \text { ROS- } \\
85-\uparrow \text { inflammatory state }\end{array}$ & d. $[95,98-103]$ \\
\hline $\begin{array}{l}\text { e. 7-26- } \uparrow \text { catecholamines } / \downarrow \text { serotonin/ } \downarrow \text { BDNF-44- } \uparrow \text { insulin resistance-70- } \uparrow \text { angiotensin II-88-50- } \uparrow \text { TNFa-41- } \uparrow \text { inflammatory } \\
\text { state }\end{array}$ & e. $[44,104-108]$ \\
\hline f. 7-26- $\uparrow$ catecholamines $/ \downarrow$ serotonin/ $\downarrow$ BDNF-44- $\uparrow$ insulin resistance-70- $\uparrow$ angiotensin II-89- $\uparrow$ SMC proliferation & f. $[95,99,101-103,109]$ \\
\hline g. 7-26- $\uparrow$ catecholamines $/ \downarrow$ serotonin/ $\downarrow$ BDNF-44- $\uparrow$ insulin resistance-70- $\uparrow$ angiotensin II-89- $\downarrow$ IGF1- $\uparrow$ SMC proliferation & g. $[101-103,109,110]$ \\
\hline h. 7-26- $\uparrow$ catecholamines $/ \downarrow$ serotonin/ $\downarrow$ BDNF-44- $\uparrow$ insulin resistance-72- $\uparrow$ platelet factors-73- $\uparrow$ hypercoagulability & h. $[17,29,99,110-117]$ \\
\hline i. 7-26- $\uparrow$ catecholamines/ $\downarrow$ serotonin/ $\downarrow$ BDNF-44- $\uparrow$ insulin resistance-72-14-55- $\uparrow$ hyperglycaemia & i. $[110,118-120]$ \\
\hline j. 7-26- $\uparrow$ catecholamines/ $\downarrow$ serotonin/ $\downarrow$ BDNF-44-12- $\uparrow$ LDL-33- $\uparrow$ oxLDL-51- $\uparrow$ hypercholesterolaemia & j. $[29,95,121,122]$ \\
\hline $\begin{array}{l}\text { k. 7-26- } \uparrow \text { catecholamines/ } \downarrow \text { serotonin/ } \downarrow \text { BDNF-44- } \uparrow \text { insulin resistance-70- } \uparrow \text { angiotensin } I I-89-\uparrow \text { hypertension-100- } \uparrow \text { ROS- } \\
85-\uparrow \text { inflammatory state }\end{array}$ & k. $[95,106-108]$ \\
\hline I. 7-27- $\uparrow$ cortisol-48-10- $\downarrow$ HDL-31- $\uparrow$ hypercholesterolaemia & I. $[14,17,29,99]$ \\
\hline m. 7-27- $\uparrow$ cortisol-48-12- $\uparrow$ LDL-33- $\uparrow$ oxLDL-51- $\uparrow$ hypercholesterolaemia & m. $[14,17,29,98,99]$ \\
\hline n. 7-27- $\uparrow$ cortisol-48-14- $\uparrow$ blood glucose-55- $\uparrow$ hyperglycaemia & n. $[14,17,29,99]$ \\
\hline $\begin{array}{l}\text { o. 7-27- } \uparrow \text { cortisol-48-14- } \uparrow \text { blood glucose-54-69- } \uparrow \text { insulin resistance-70- } \uparrow \text { angiotensin II-89- } \uparrow \text { hypertension-100- } \uparrow \text { ROS }-85- \\
\uparrow \text { inflammatory state }\end{array}$ & o. [98-100] \\
\hline $\begin{array}{l}\text { p. 7-27- } \uparrow \text { cortisol-48-14- } \uparrow \text { blood glucose-54-69- } \uparrow \text { insulin resistance-70- } \uparrow \text { angiotensin II-88-50- } \uparrow \text { TNFa-41- } \uparrow \text { inflammatory } \\
\text { state }\end{array}$ & p. [123] \\
\hline q. 7-27- $\uparrow$ cortisol-48-14- $\uparrow$ blood glucose-54-69- $\uparrow$ insulin resistance-70- $\uparrow$ angiotensin II-89- $\uparrow$ SMC proliferation & q. [99] \\
\hline r. 7-27- $\uparrow$ cortisol-48-14- $\uparrow$ blood glucose-54-69- $\uparrow$ insulin resistance-70- $\uparrow$ angiotensin II-89- $\downarrow$ IGF1- $\uparrow$ SMC proliferation & r. $[101-103,109]$ \\
\hline s. 7-27- $\uparrow$ cortisol-48-14- $\uparrow$ blood glucose-54-69- $\uparrow$ insulin resistance-72- $\uparrow$ platelet factors-73- $\uparrow$ hypercoagulability & s. $[17,29,99,111-117]$ \\
\hline t. 7-27- $\uparrow$ cortisol-48-14- $\uparrow$ blood glucose-54-69- $\uparrow$ insulin resistance-72- $\uparrow$ vasodilation & t. [123] \\
\hline $\begin{array}{l}\text { u. 7-27- } \uparrow \text { cortisol-48-14- } \uparrow \text { blood glucose-54-19- } \downarrow \text { adiponectin-38- } \uparrow \text { TNFa- } 41-\uparrow \text { P.gingivalis-43- } \uparrow \text { periodontitis-64- } \uparrow \text { platelet } \\
\text { factors-73- } \uparrow \text { hypercoagulability }\end{array}$ & u. $[17,29,99,111-117,124]$ \\
\hline v. 7-27- $\uparrow$ cortisol-48-14- $\uparrow$ blood glucose-54-19- $\downarrow$ adiponectin-39- $\uparrow$ insulin resistance- $72-\downarrow$ vasodilation & v. [123] \\
\hline w. 7-27- $\uparrow$ cortisol-48-14- $\uparrow$ blood glucose-54-19- $\downarrow$ adiponectin-39- $\uparrow$ SMC proliferation & W. [125] \\
\hline x. 7-27- $\uparrow$ cortisol-48-14- $\uparrow$ blood glucose-54- $\uparrow$ PI3K:MAPK-69- $\uparrow$ insulin resistance-72-14-55- $\uparrow$ hyperinsulinaemia & x. $[17,20,29,99]$ \\
\hline y. 7-27- $\uparrow$ cortisol-48-14- $\uparrow$ blood glucose-53- $\uparrow$ NO depletion-57- $\uparrow$ SMC proliferation & y. $[17,29,99,126]$ \\
\hline z. 7-27- $\uparrow$ cortisol-48-14- $\uparrow$ blood glucose-53- $\uparrow$ NO depletion-57- $\downarrow$ vasodilation & z. $[17,29,99,127]$ \\
\hline aa. 7-27- $\uparrow$ cortisol-48-14- $\uparrow$ blood glucose-54- $\uparrow$ angiotensin II-89- $\uparrow$ hypertension-100- $\uparrow$ ROS-85- $\uparrow$ infla & aa. $[17,29,98,99]$ \\
\hline
\end{tabular}

$\uparrow$ denotes up regulation/increase, $\downarrow$ denotes down regulation/decrease, $x-y-z$ indicates pathway connecting $x$ to $y$ to $z$

FFA free fatty acids, IGF 1 insulin-like growth factor-1, LDL low-density lipoprotein, MAPK mitogen-activated protein (MAP) kinase, NO nitric oxide, oxLDL oxidized LDL, P. gingivalis Porphyromonas gingivalis, PI3K phosphatidylinositol 3-kinase, PI3K:MAPK ratio of PI3K to MAPK, ROS reactive oxygen species, SMC smooth muscle cell, TNFa tumor necrosis factor-a

which can lead to increased inflammation [24] as well as lower brain derived neurotrophic factor (BDNF) activity [25]. (Fig. 1, Pathway: 7-27-48-14-54-89-hypertension100-inflammatory state).

Increased insulin resistance can cause increased serum levels of platelet factors and thus increases the potential for hypercoagulability [26, 27]. Additionally, increased insulin resistance has been found to be associated with increased levels of inflammatory cytokine TNF-a and increased levels of inflammation [28] as shown in the integrated model in pathway: 7-27-48-14-54-69-70-8850-41-inflammatory state.
Elevations in glucocorticoids inhibit lipoprotein lipase activity leading to diminished triglyceride clearance, decreased HDL concentrations, and increase in LDL serum concentrations [29]. Additionally, high levels of glucocorticoids suppress hepatic LDL receptors and delay LDL clearance [30]. This shows how depression can affect cholesterolaemia through pathways 7-2748-10-31-hypercholesterolaemia and 7-27-48-12-3351-hypercholesterolaemia.

The integrated model shows how depression may affect coagulation and vasodilation through pathways: 7-26-catecholamines-44-73-hypercoagulability and 7- 
26-catecholamines-44-57-vasodilation. Elevated serum levels of catecholamines, such as norepinephrine, may promote hypercoagulability by platelet activation through direct agonist effects, and endothelial injury by increased hemodynamic stress on vascular walls [31].

Decreased levels of BDNF have been observed in depressed patients [32, 33]. Normal or increased levels of BDNF have been found to have positive effects on some of the underlying pathogenesis of CHD including improved glucose metabolism [34]. Thus a reduction of BDNF can thus serve to reduce glucose control, which can have a feedback effect by inhibiting the cerebral output of BDNF [35] as shown in pathway: 726-BDNF-44-72-14-55-hyperglycaemia.

However, BDNF may increase oxidative stress through activation of $\mathrm{NAD}(\mathrm{P}) \mathrm{H}$ oxidase [36]. Thus BDNF could have a negative impact on the pathogenesis of CHD and plaque stability. BDNF is thought to positively affect the action and secretion of insulin, ghrelin and leptin [34]. (Fig. 1, Pathway: 7-26-BDNF44-insulin resistance).

Increased levels of serotonin could serve to up-regulate some of the underlying pathogenesis of CHD. Alterations in serotonergic neuronal function in the central nervous system occur in patients with major depression [37]. Activated platelets secrete serotonin in substantial quantities which can cause vasoconstriction [38]. Additionally, serotonin has a role in platelet aggregation and proliferation of vascular endothelial cells [39, 40]. (Fig. 1, Pathways: serotonin-94-57-SMC proliferation and serotonin-94-57vasodilation).

It is apparent that depression directly and indirectly affects a plethora of interconnected pathogenetic mechanisms. Each CHD hallmark and pathogenetic trait can amplify the patient's risk of CHD, thus necessitating an integrated, multi-faceted therapeutic approach.

\section{Biomarkers of coronary heart disease}

While the pathogenesis of depression is not completely understood, the possible pathogenetic effect of depression on CHD could be better understood through the measurement of serological biomarkers [41]. Biomarkers can be used as indicators of an underlying disorder. The measurement of specific biomarkers enables the prediction of the RR for CHD associated with the biomarker [42-44]. This can allow for the quantification of the effects of depression on the pathogenesis of CHD.

To simplify the integrated model, serological biomarkers (which can be easily measured) are used to link the effect of depression to the corresponding RR of CHD. Figure 2 presents a comparison of the $R R$ associated with an array of serological biomarkers per 1-standard deviation increase in the biomarker [9].

\section{Effects of depression on coronary heart disease}

The pathogenesis of depression in CHD and the integrated model in Fig. 1 could be used to account for the impact that depression has on the serological biomarkers of CHD (Fig. 2). The integrated model can be simplified into a 'connection graph', which shows all the connections between depression and the serological biomarkers of CHD without neglecting the underlying complexity of CHD. The relevant pathways of Fig. 1 are shown on the connection lines of Fig. 3.

For further clarity the biomarkers previously shown in Fig. 2 were divided into eight classes. Furthermore, the connection lines are scaled according to the RR associated with the biomarker. Thus, the greater the RR for $\mathrm{CHD}$ of a biomarker the thicker the connection line will be to that biomarker. For example, the RR for CHD associated with leptin is relatively low, thus the connection line between depression and leptin is thin. The RR for $\mathrm{CHD}$ associated with insulin resistance is large thus the connection line between depression and insulin resistance is thick.

While the connection lines give an indication of which biomarkers of $\mathrm{CHD}$ are affected by depression they do not indicate the nature of the connection. The effect of the connection are thus shown by arrows in Fig. 3 which indicate whether the effect on the biomarker is to increase $(\uparrow)$ or decrease risk $(\downarrow)$.

The interconnectedness of depression is immediately evident from Fig. 3. Depression is seen to have connections to the vast majority of the CHD biomarkers considered here. It is evident that depression is widely connected to inflammatory and metabolic biomarkers. Additionally, there are connections between all the lipid biomarkers and some of the markers of vascular function, oxidative stress and coagulation.

Increased levels of inflammation have been reported in patients with depression $[45,46]$. It has even been suggested that increased inflammatory markers may be a risk factor for the progression of depression [45]. Increased levels of inflammatory markers such as the cytokines CRP, IL- 6 and TNF- $\alpha$ have been measured in patients with depression [47, 48], regardless of a causal link between depression and inflammation.

Changes in osteoprotegerin may be possible due to the observation of decreased bone density [49] and an increased risk of osteoporosis in depressed patients [50]. Thus inflammation and depression seem intertwined and could account for some of the increased CHD risk due to depression.

Many of the metabolic aspects of depression could be mediated through the actions of cortisol and BDNF. Increased serum levels of cortisol have been noted in depressed patients $[12,51]$, and may lead to other metabolic complications such as hyperglycaemia, hyperinsulinaemia 


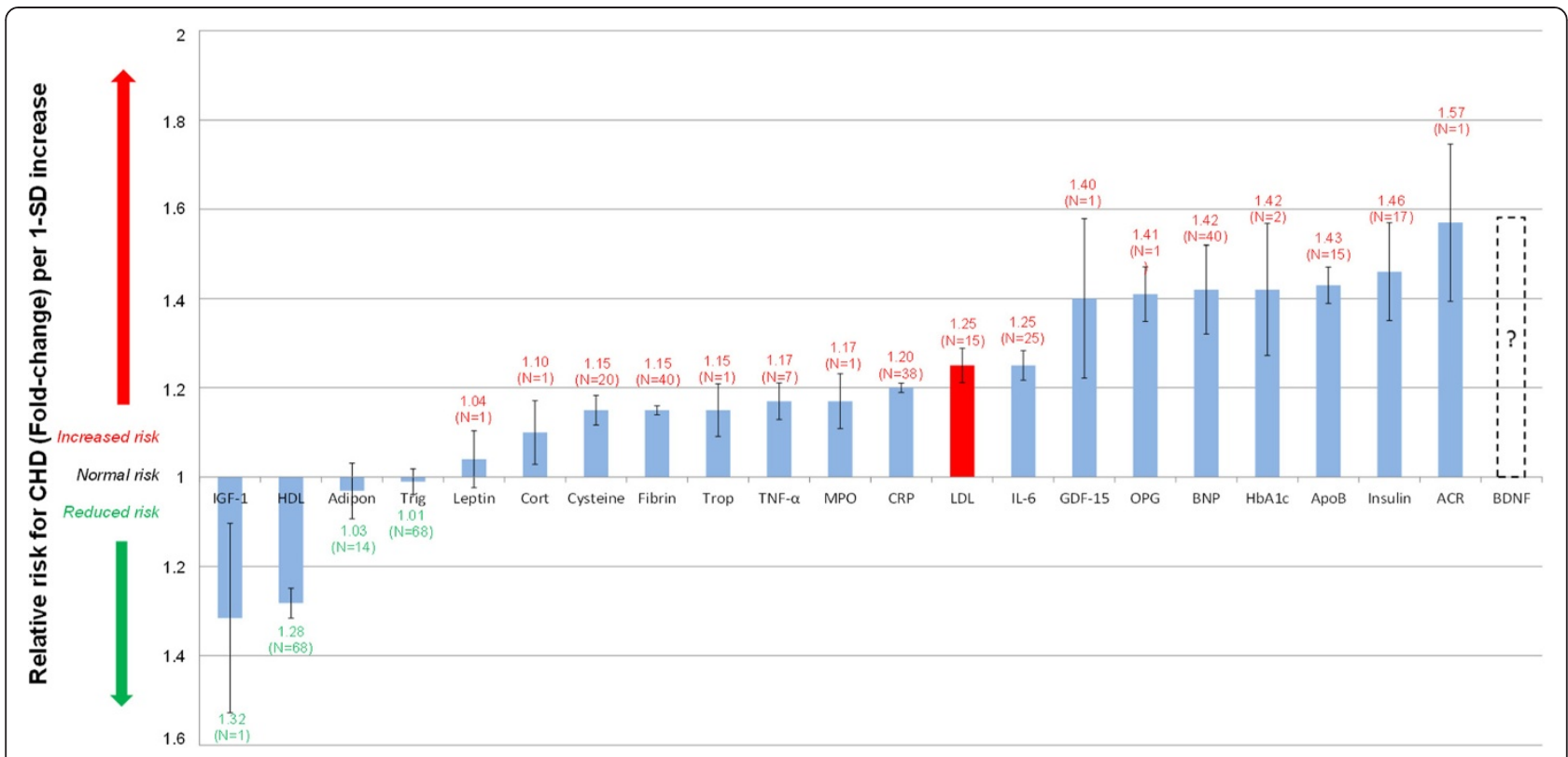

Fig. 2 Normalized relative risks (fold-change) of salient current biomarkers or of potential serological biomarkers for CHD. Note. From "How do high glycemic load diets influence coronary heart disease?" by Mathews M, Liebenberg L, Mathews EH Nutr Metab 2015;12:6 [9]. Increased IGF-1 and HDL levels are associated with a moderately decreased CHD risk. (IGF-1 and HDL levels are significantly inversely correlated to relative risk for CHD.) N indicates number of trials; I, standard error; ACR, albumin-to-creatinine ratio; Adipo, adiponectin; ApoB, apolipoprotein-B; BDNF, brainderived neurotrophic factor; BNP, B-type natriuretic peptide; Cort, cortisol; CRP, C-reactive protein; Cysteine, Homocysteine; Fibrin, fibrinogen; GDF15, growth-differentiation factor-15; HbA1c, glycated hemoglobin A1c; HDL, high-density lipoprotein; IL-6, interleukin-6; IGF-1, insulin-like growth factor-1; LDL, low-density lipoprotein; MPO, myeloperoxidase; RANKL or OPG, osteoprotegerin; TNF-a, tumor necrosis factor-a; Trop, troponins; Trigl, triglycerides

and hypercholesterolemia. Thus, BDNF and cortisol may possibly explain the link between depression and glycated hemoglobin $\left(\mathrm{HbA}_{1 \mathrm{c}}\right)$, insulin resistance, $\mathrm{LDL}$ and $\mathrm{HDL}$ $[15,19,29]$.

BDNF has frequently been found to be reduced in patients with depression with the implication being that reduced levels of BDNF may be a suitable biomarker for depression [52]. Beyond this intriguing possibility for its use as a biomarker for depression it is postulated here that reduced levels of BDNF may also be a suitable prospective biomarker for CHD risk. This is indicated by the dashed bar in Figs. 2 and 3 [53].

Adiponectin levels in patients with depression have been found to be lower than that of healthy controls independent of conventional factors such as coronary heart disease and metabolic disorders [54]. This could imply that lowered adiponectin levels associated with depression could indicate increased risk for CHD.

The connection between depression and the lipid biomarkers is not as clear as between depression and inflammation [55]. Conflicting evidence surrounds the association between depression and cholesterol levels. Some studies have found that HDL, LDL and Apo B levels are increased in patients with depression [56], others have found that depression is associated with decreased HDL and increased LDL levels [57], yet others have found that both LDL and HDL decrease with depression [55]. Regardless of the unknown effect between cholesterol and depression it is evident that there may be some connection between the two.

The effect of depression on other lipid biomarkers such as leptin are also not clearly elucidated as both increased [58] and decreased levels have been noted in patients with depression [59]. Some of the changes in leptin may be mediated to some degree by decrease in BDNF which are observed in depression [60].

The impact of depression on vascular function may be mediated by increased serum levels of homocysteine and B-type natriuretic peptide (BNP) which are evident in patients with major depressive disorder $[61,62]$. Increased serum levels of homocysteine and BNP are both associated with an increased risk of CHD [63, 64]. This indicates a possible connection between depression and CHD through an underlying vascular action.

A connection may exist between depression and both oxidative stress and coagulation in the increased levels of serum myeloperoxidase (MPO) and fibrinogen respectively $[47,48]$. Thus it is evident that the use of biomarkers may further elucidate the connections between underlying pathogenesis which may be common 


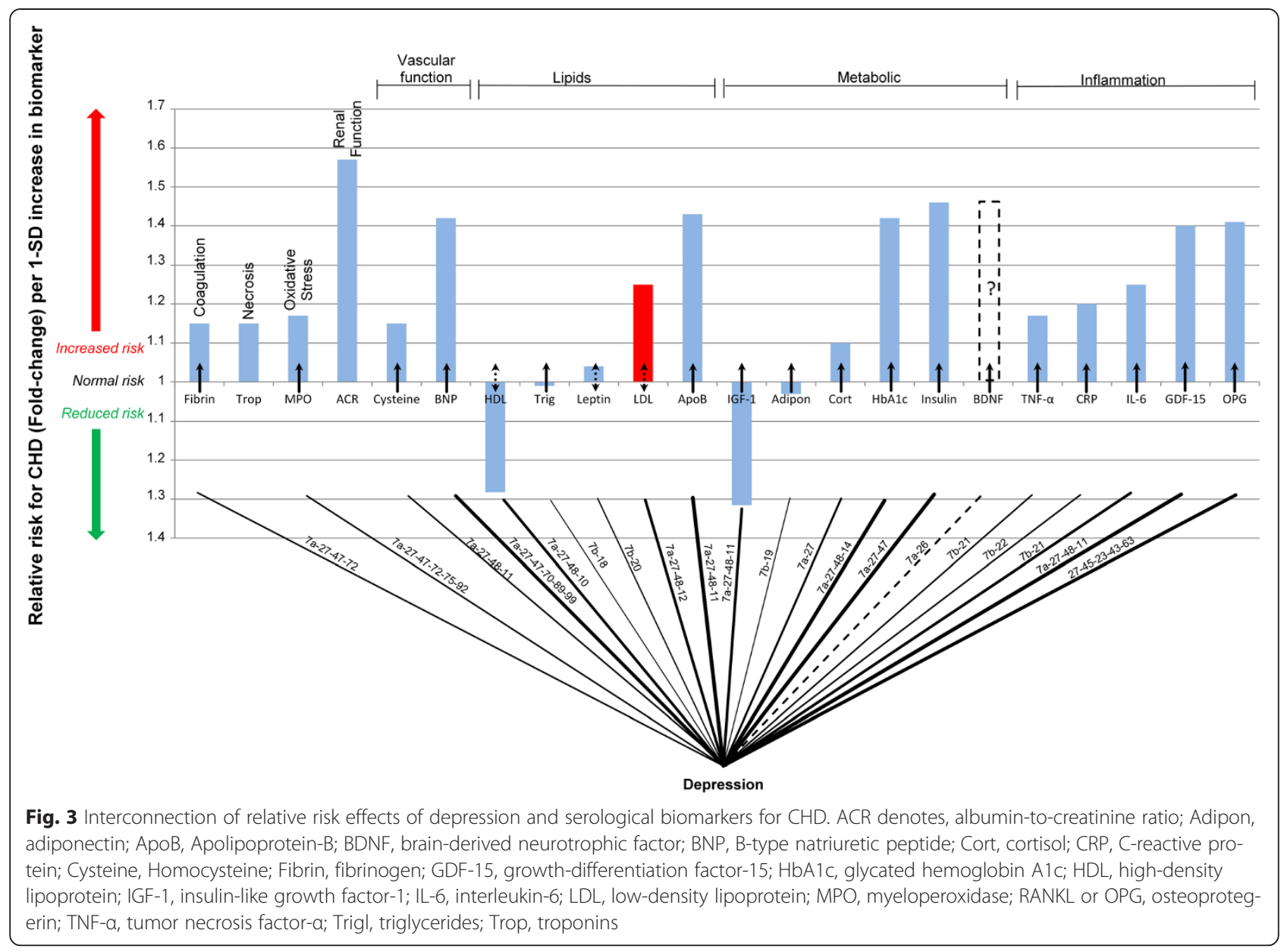

between both depression and CHD. This may help understanding the relationship between depression and the increased risk for CHD.

\section{Antidepressants}

To attempt to elucidate the effects of antidepressant treatment of depression on the pathogenesis of CHD the integrated model in Fig. 1 was used to formulate a 'connection graph' for the use of selective serotonin reuptake inhibitor (SSRI) antidepressants. SSRI's were chosen as they have been linked to greater likelihood of positive outcome after CHD event [65]. Furthermore, certain other antidepressants, such as tricyclic antidepressants, have been linked to increased incidence of adverse CHD outcomes [66].

The serological biomarkers which are modified by use of SSRI's are presented in Fig. 4. Figure 4 is a 'connection graph' presented in the same manner as was Fig. 3. The 'connection graph' for SSRI antidepressants elucidates known changes in serological biomarkers. The paths upon which SSRI's may act to influence these biomarkers are indicated on the connection lines.
The serum levels of CRP and IL- 6 have been observed to be reduced by SSRI use in the depressed [67]. Tumor necrosis factor- $\alpha$ (TNF- $\alpha)$ may play a role in the responsiveness of SSRI use, with increased levels predicting non-responsiveness [68]. The modification of these biomarkers by SSRI's could serve to decrease the risk for CHD. Osteoprotegerin is decreased by the use of some SSRI's [69], which may serve to decrease the risk of CHD. SSRI's affect the entire range of inflammatory biomarkers in a manner that would suggest CHD risk decreases.

The metabolic links between CHD and SSRI's are most likely mediated by the effect of increased BDNF levels after SSRI treatment [51, 52]. SSRI's also have an effect on insulin like growth factor 1 (IGF-1) which is low in children using SSRI's [70] and interruption of SSRI treatment leads to increased serum levels thereof [71]. Increased insulin sensitivity, which has been noted in patients who have remitted depression using SSRI's [72], could also serve to positively affect serum glucose levels. Increased adiponectin levels have been found to occur due to, inhibition of TNF- $\alpha$ production, after remittance of depression [73]. 


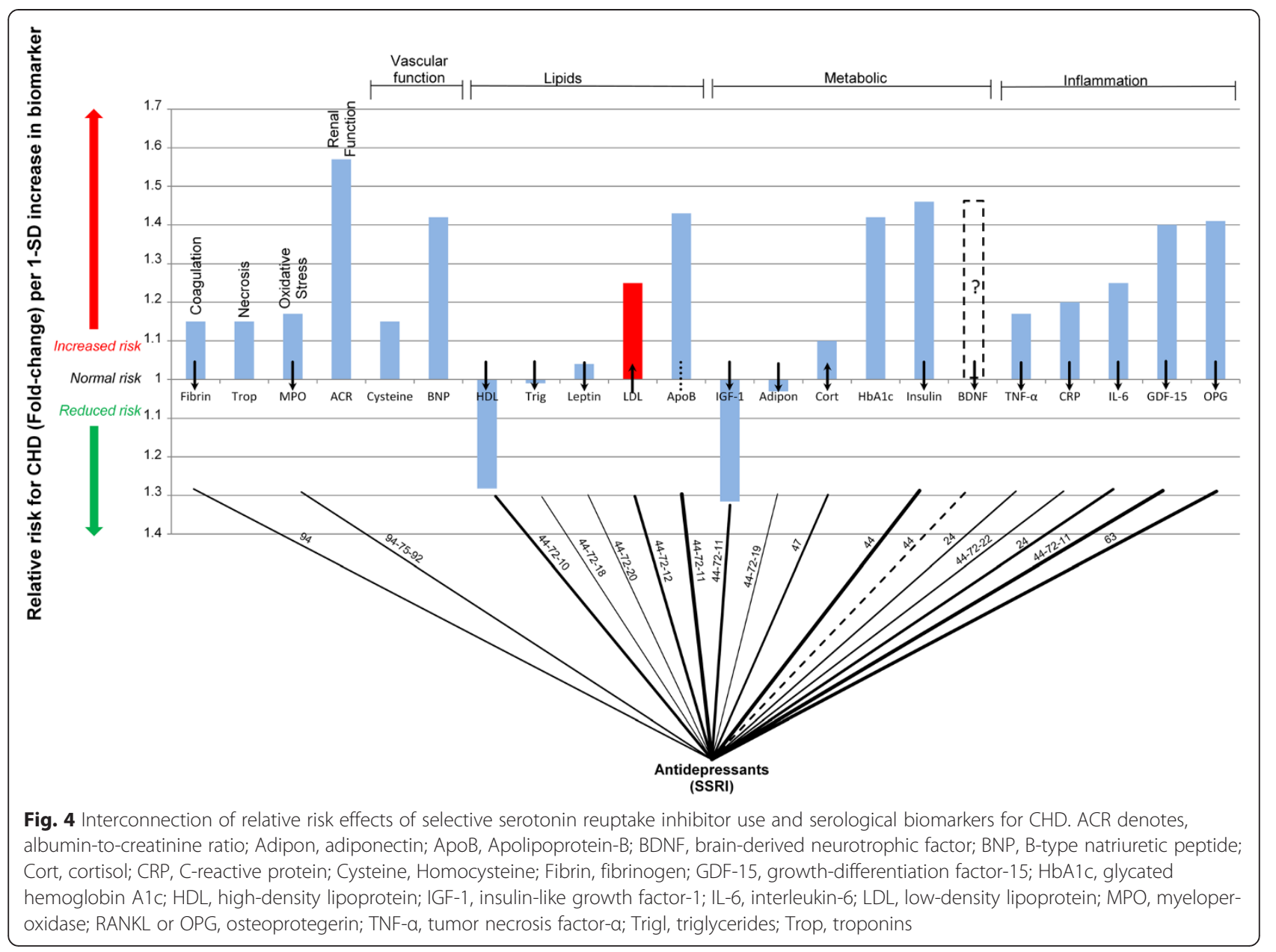

Cortisol levels have been recorded as both increased $[67,74]$, and decreased [75] in patients using SSRI's, thus a possible link exists between SSRI use and serum cortisol levels. However, as a whole the effect of SSRI's on the metabolic biomarkers would appear to be positive, as shown in Fig. 4. The "connection graph" suggests that the effect of SSRI's on the metabolic biomarkers is such that it would reduce CHD risk.

The connections between SSRI antidepressants and the lipid biomarkers, shown in Fig. 4, are due to increased serum levels of LDL and HDL cholesterol noted in patients treated with SSRI's [76, 77]. Current research has shown that serum ghrelin levels can be normalized [78] which could lead to changes in eating habits and thereby affect leptin levels [79]. The net effects of SSRI's on the lipid profile, in terms a patients risk for CHD, may be somewhat uncertain. This is due to the positive changes in HDL levels, negative changes in LDL levels, no substantial change in leptin levels and an unknown effect on Apo B.

Figure 4 shows the improvements of oxidative stress which may be possible with SSRI [80]. These changes in oxidative stress may be present in patients as changes in MPO serum levels [81]. Furthermore, Fig. 4 shows how serum levels of fibrinogen can be reduced by SSRI use [67]. These changes would present a lower risk for CHD according to biomarker RR prediction.

Unfortunately the fully quantified effect of the different biomarkers, modified by SSRI use, is not shown by the "connection graph" in Fig. 4. The "connection graph" only shows if a biomarker is affected and if this effect is positive or negative. Future studies will be required to quantify the effect of each biomarker individually on the risk for CHD. Furthermore when considering the implications of antidepressant use on the biomarkers of CHD it is important to note that antidepressants would likely only prove beneficial in patients with depression and not in the general population $[65,82]$.

It must be noted that like all pharmacotherapeutic therapies there is always the possibility for some adverse effects [83-85] and possible drug interactions [86]. However, SSRI treatment has proved to be both safe and effective in treating depression in patients with CHD [87]. 


\section{Discussion}

The 'connection graph' for depression presented in Fig. 3 indicates that the effect of depression on CHD pathogenesis, as measured by effects on serological biomarkers of CHD, would likely serve to increase a depressed patients risk for CHD. The magnitude of this effect can be quantified through determining the RR for CHD offered by depression.

Observational studies considering the incidence of $\mathrm{CHD}$ in depressed patients may provide these answers. A meta-analysis of such studies comprising 124,509 patients in 21 studies found that the depressed had an increased RR for CHD of 1.90 (1.49 to 2.42) compared to healthy controls [4].

It is known that antidepressants such as SSRI's can mediate the symptoms of depression [88] and impact the biomarkers of CHD in such a manner that would appear to be positive in terms of CHD risk (Fig. 4). Again the magnitude of this effect is evident in the potential reduction in CHD risk due to SSRI's use in a depressed population initially without CHD [7].

In an observational study of 93,653 patients with depression, without $\mathrm{CHD}$, it was found that patients, who had 12 or more weeks of antidepressant treatment, had a RR for CHD of 0.48 (0.44 to 0.52) compared to patients not treated. When using our risk presentation this equates to a possible 2.08-fold reduction in CHD risk. The observational nature of this study must be noted and conclusions on treatment cannot be directly drawn from these results. The results may allude to primary prevention of CHD due to SSRI use in the depressed [7].

Some of the important aspects of depression may be the increase in inflammation and dysregulation of metabolism evident through the increases in inflammatory and metabolic biomarkers [15, 47, 48, 89]. Comparing the 'connection graphs' of depression and SSRI use it is clear that some of the manners in which depression effects the serological biomarkers are mediated by SSRI's.

These effects include positive impacts on coagulation, oxidative stress and metabolism which are deregulated by depression. The effects of depression on lipids are not wholly clear (Fig. 3) and accordingly the effects of SSRI's on these would most likely not account for the decreased risk observed (Fig. 4).

Interestingly the inflammatory biomarkers which are all negatively influenced by depression are positively mediated by SSRI usage. This may highlight the importance of inflammation in the pathogenesis of CHD especially in how depression influences it. A combination of these changes presents the possible action of a risk reduction, such as those observed in depressed patients using SSRI's [7].

The data from Fig. 3 and Fig. 4 show that inflammation and metabolic dysregulation may be key aspects in the pathogenesis of CHD $[15,45,46,90]$. These aspects increase in depression and may play a part in the 1.90fold increased risk for CHD. With the use of SSRI antidepressants these factors decrease and may present up to a 2.08-fold reduction in CHD risk. This further highlights the importance of inflammation and metabolic dysregulation the pathogenesis of CHD.

Depression not only has direct effects but can have further negative effects on the treatment and secondary prevention of CHD. Depressed patients typically have trouble adhering to medication and intervention therapy [91]. This could serve to explain some of the increased risk that is associated with depression after a CHD event [92]. These and direct actions of depression on CHD adds credence to the recommendation that depression should be elevated to the status of risk factor for poor prognosis in patients with CHD [93].

Based on the evidence we believe that the CHD risk associated with depression is substantial and should garner a similar level of public interest as does other risk factors such as smoking, high cholesterol and treatments such as statin therapy. We agree very strongly with recommendations presented by the American Heart Association that depression should be screened for regardless of a causal link between improved depression and CHD risk [94].

Further research is required in the form of adequately powered interventional trials on the efficacy of SSRI's in primary prevention of CHD in depressed patients. Additionally, studies are required to determine the risk for $\mathrm{CHD}$ that would be associated with decreased serum levels of BDNF.

\section{Conclusions}

It is apparent that depression has a wide ranging impact on the pathogenesis of CHD with these effects notable in changes in CHD biomarkers. However, depression can be mediated through the use of antidepressants such as SSRI's. These antidepressants may mediate some of the negative pathogenetic effects of depression on CHD. Such effects are noted in the normalization of the CHD biomarkers in patients using SSRI's. These effects result in a decreased risk for CHD observed in depressed patients using SSRI antidepressants.

\section{Competing interests}

The authors declare that they have no competing interests.

\section{Authors' contributions}

MM complied and revised the draft manuscript, did the literature reviews and analysed the effect of depression on the biomarkers. EM conceived the study and helped to compile and revise the draft manuscript. LL helped carry out initial literature reviews and aided in the drafting and revising of the manuscript. All authors read and approved the final manuscript. 


\section{Acknowledgements}

The angel investor was Dr Arnold van Dyk. We also acknowledge the fact that the integrated view is relevant to other lifestyle issues and for full comprehension will have to be replicated again in other articles describing these.

Received: 22 April 2015 Accepted: 24 July 2015

Published online: 01 August 2015

\section{References}

1. Murray CJ, Vos T, Lozano R, Naghavi M, Flaxman AD, Michaud C, et al. Disability-adjusted life years (DALYs) for 291 diseases and injuries in 21 regions, 1990-2010: a systematic analysis for the Global Burden of Disease Study 2010. Lancet. 2013;380:2197-223.

2. Mathers CD, Boerma T, Fat DM. Global and regional causes of death. Br Med Bull. 2009;92:7-32.

3. Rugulies R. Depression as a predictor for coronary heart disease: a review and meta-analysis. Am J Prev Med. 2002;23:51-61.

4. Nicholson A, Kuper $\mathrm{H}$, Hemingway $H$. Depression as an aetiologic and prognostic factor in coronary heart disease: a meta-analysis of 6362 events among 146538 participants in 54 observational studies. Eur Heart J. 2006:27:2763-74

5. Barefoot JC, Helms MJ, Mark DB, Blumenthal JA, Califf RM, Haney TL, et al. Depression and long-term mortality risk in patients with coronary artery disease. Am J Cardiol. 1996;78:613-7.

6. Carney RM, Rich MW, Freedland KE, Saini J, Simeone C, Clark K. Major depressive disorder predicts cardiac events in patients with coronary artery disease. Psychosom Med. 1988;50:627-33.

7. Scherrer JF, Garfield LD, Lustman PJ, Hauptman PJ, Chrusciel T, Zeringue A, et al. Antidepressant drug compliance: reduced risk of $\mathrm{Ml}$ and mortality in depressed patients. Am J Med. 2011;124:318-24.

8. Lusis AJ, Weiss JN. Cardiovascular networks systems-based approaches to cardiovascular disease. Circulation. 2010;121:157-70.

9. Mathews MJ, Liebenberg L, Mathews EH. How do high glycemic load diets influence coronary heart disease? Nutr Metab. 2015:12:6. doi:10.1186/ s12986-015-0001-x

10. Musselman DL, Evans DL, Nemeroff CB. The relationship of depression to cardiovascular disease: epidemiology, biology, and treatment. Arch Gen Psychiatry. 1998:55:580-92.

11. Nemeroff CB, Vale WW. The neurobiology of depression: inroads to treatment and new drug discovery. J Clin Psychiatry. 2005;66:5-13.

12. Vreeburg SA, Hoogendijk WJ, van Pelt J, DeRijk RH, Verhagen JC, van Dyck $R$, et al. Major depressive disorder and hypothalamic-pituitary-adrenal axis activity: results from a large cohort study. Arch Gen Psychiatry. 2009;66:617-26.

13. Joynt KE, Whellan DJ, O'Connor CM. Depression and cardiovascular disease: mechanisms of interaction. Biol Psychiatry. 2003;54:248-61.

14. Weissman C. The metabolic response to stress: an overview and update Anesthesiology. 1990;73:308-27.

15. Lambillotte C, Gilon P, Henquin J-C. Direct glucocorticoid inhibition of insulin secretion. An in vitro study of dexamethasone effects in mouse islets. J Clin Invest. 1997;99:414-23.

16. Hennings J, Ising M, Grautoff S, Himmerich H, Pollmächer T, Schaaf L. Glucose tolerance in depressed inpatients, under treatment with mirtazapine and in healthy controls. Exp Clin Endocrinol Diabetes. 2010;118:98-100.

17. Walker BR. Glucocorticoids and cardiovascular disease. Eur J Endocrinol. 2007:157:545-59.

18. Kyrou I, Tsigos C. Stress hormones: physiological stress and regulation of metabolism. Curr Opin Pharmacol. 2009;9:787-93.

19. Lafontan M, Langin D. Lipolysis and lipid mobilization in human adipose tissue. Prog Lipid Res. 2009;48:275-97.

20. Muniyappa R, Montagnani M, Koh KK, Quon MJ. Cardiovascular actions of insulin. Endocr Rev. 2007;28:463-91.

21. Mitchell BM, Webb RC. Impaired vasodilation and nitric oxide synthase activity in glucocorticoid-induced hypertension. Biol Res Nurs. 2002;4:16-21.

22. Karagiannis A, Mikhailidis DP, Athyros VG, Kakafika Al, Tziomalos K, Liberopoulos EN, et al. The role of renin-angiotensin system inhibition in the treatment of hypertension in metabolic syndrome: are all the angiotensin receptor blockers equal? Expert Opin Ther Targets. 2007;11:191-205.

23. Epel ES. Psychological and metabolic stress: a recipe for accelerated cellular aging. Hormones. 2009;8:7-22.
24. Wolkowitz OM, Reus VI, Mellon SH. Of sound mind and body: depression, disease, and accelerated aging. Dialogues Clin Neurosci. 2011;13:25-39.

25. Grant MM, Barber VS, Griffiths HR. The presence of ascorbate induces expression of brain derived neurotrophic factor in $\mathrm{SH}-\mathrm{SY} 5 \mathrm{Y}$ neuroblastoma cells after peroxide insult, which is associated with increased survival. Proteomics. 2005:5:534-40.

26. Cimenti C, Schlagenhauf A, Leschnik B, Schretter M, Tschakert G, Gröschl W, et al. Low endogenous thrombin potential in trained subjects. Thromb Res. 2013;131:e281-e5.

27. Rauramaa R, Salonen JT, Seppänen K, Salonen R, Venäläinen J, Ihanainen M et al. Inhibition of platelet aggregability by moderate-intensity physical exercise: a randomized clinical trial in overweight men. Circulation. 1986;74:939-44.

28. Gu H, Tang C, Peng $K$, Sun $H$, Yang $Y$. Effects of chronic mild stress on the development of atherosclerosis and expression of toll-like receptor 4 signaling pathway in adolescent apolipoprotein E knockout mice. J Biomed Biotechnol. 2009:2009:613879.

29. Costa R, Sanches A, Cunha TS, Moura MJCS, Tanno AP, Casarini DE. Dyslipidemia induced by stress. Dyslipidemia - From Prevention to Treatment. Shanghai: InTech; 2011. p. 367-90.

30. Stoney CM, Finney M. Cholesterol and lipoproteins. Encyclopedia of stress. 1st ed. 2000. p. 454-9.

31. Carney RM, Freedland KE, Veith RC. Depression, the autonomic nervous system, and coronary heart disease. Psychosom Med. 2005;67:S29-33.

32. Karege F, Perret G, Bondolfi G, Schwald M, Bertschy G, Aubry J-M. Decreased serum brain-derived neurotrophic factor levels in major depressed patients. Psychiatry Res. 2002;109:143-8.

33. Karege F, Bondolfi G, Gervasoni N, Schwald M, Aubry J-M, Bertschy G. Low brain-derived neurotrophic factor (BDNF) levels in serum of depressed patients probably results from lowered platelet BDNF release unrelated to platelet reactivity. Biol Psychiatry. 2005;57:1068-72.

34. Rao AA, Sridhar GR, Srinivas B, Das UN. Bioinformatics analysis of functional protein sequences reveals a role for brain-derived neurotrophic factor in obesity and type 2 diabetes mellitus. Med Hypotheses. 2008;70:424-9.

35. Krabbe K, Nielsen A, Krogh-Madsen R, Plomgaard P, Rasmussen P, Erikstrup

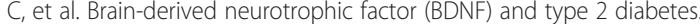
Diabetologia. 2007:50:431-8.

36. Ejiri J, Inoue N, Kobayashi S, Shiraki R, Otsui K, Honjo T, et al. Possible role of brain-derived neurotrophic factor in the pathogenesis of coronary artery disease. Circulation. 2005:112:2114-20.

37. Owens MJ, Nemeroff CB. Role of serotonin in the pathophysiology of depression: focus on the serotonin transporter. Clin Chem. 1994:40:288-95.

38. MCFadden EP, Clarke JG, Davies GJ, Kaski JC, Haider AW, Maseri A. Effect of intracoronary serotonin on coronary vessels in patients with stable angina and patients with variant angina. N Engl J Med. 1991;324:648-54

39. Vikenes K, Farstad M, Nordrehaug JE. Serotonin is associated with coronary artery disease and cardiac events. Circulation. 1999:100:483-9.

40. De Clerck F. Effects of serotonin on platelets and blood vessels. J Cardiovasc Pharmacol. 1991:17:S6

41. Gardner A, Boles RG. Beyond the serotonin hypothesis: mitochondria inflammation and neurodegeneration in major depression and affective spectrum disorders. Prog Neuropsychopharmacol Biol Psychiatry. 2011;35:730-43.

42. Vasan RS. Biomarkers of cardiovascular disease molecular basis and practical considerations. Circulation. 2006;113:2335-62.

43. Libby P. Atherosclerosis in inflammation. Nature. 2002:420:868-74

44. Packard RR, Libby P. Inflammation in atherosclerosis: from vascular biology to biomarker discovery and risk prediction. Clin Chem. 2008:54:24-38.

45. Pasco JA, Nicholson GC, Williams LJ, Jacka FN, Henry MJ, Kotowicz MA, et al. Association of high-sensitivity C-reactive protein with de novo major depression. Br J Psychiatry. 2010;197:372-7.

46. Howren MB, Lamkin DM, Suls J. Associations of depression with C-reactive protein, IL-1, and IL-6: a meta-analysis. Psychosom Med. 2009;71:171-86.

47. Kop WJ, Gottdiener JS, Tangen CM, Fried LP, McBurnie MA, Walston J, et al. Inflammation and coagulation factors in persons $>65$ years of age with symptoms of depression but without evidence of myocardial ischemia. Am J Cardiol. 2002:89:419-24

48. Vaccarino V, Brennan M-L, Miller AH, Bremner JD, Ritchie JC, Lindau F, et al. Association of major depressive disorder with serum myeloperoxidase and other markers of inflammation: a twin study. Biol Psychiatry. 2008;64:47683 
49. Yirmiya R, Bab I. Major depression is a risk factor for low bone mineral density: a meta-analysis. Biol Psychiatry. 2009;66:423-32.

50. Cizza G, Primma S, Csako G. Depression as a risk factor for osteoporosis. Trends Endocrinol Metab. 2009;20:367-73.

51. Lee B-H, Kim Y-K. The Roles of BDNF in the Pathophysiology of Major Depression and in Antidepressant Treatment. Psychiatry Investig. 2010;7:231-5. doi:10.4306/pi.2010.7.4.231.

52. Sen S, Duman R, Sanacora G. Serum brain-derived neurotrophic factor, depression, and antidepressant medications: meta-analyses and implications. Biol Psychiatry. 2008;64:527-32.

53. Jiang H, Liu Y, Zhang Y, Chen Z-Y. Association of plasma brain-derived neurotrophic factor and cardiovascular risk factors and prognosis in angina pectoris. Biochem Biophys Res Commun. 2011;415:99-103.

54. Lehto S, Huotari A, Niskanen L, Tolmunen T, Koivumaa-Honkanen H, Honkalampi K, et al. Serum adiponectin and resistin levels in major depressive disorder. Acta Psychiatr Scand. 2010;121:209-15.

55. Tedders SH, Fokong KD, McKenzie LE, Wesley C, Yu L, Zhang J. Low cholesterol is associated with depression among US household population. J Affect Disord. 2011;135:115-21.

56. Sarandol A, Sarandol E, Eker SS, Karaagac EU, Hizli BZ, Dirican M, et al. Oxidation of apolipoprotein B-containing lipoproteins and serum paraoxonase/arylesterase activities in major depressive disorder. Prog Neuropsychopharmacol Biol Psychiatry. 2006;30:1103-8

57. Chrapko WE, Jurasz P, Radomski MW, Lara N, Archer SL, Le Mellédo J-M. Decreased platelet nitric oxide synthase activity and plasma nitric oxide metabolites in major depressive disorder. Biol Psychiatry. 2004;56:129-34.

58. Pasco JA, Jacka FN, Williams LJ, Henry MJ, Nicholson GC, Kotowicz MA, et al. Leptin in depressed women: cross-sectional and longitudinal data from an epidemiologic study. J Affect Disord. 2008;107:221-5.

59. Jow G-M, Yang T-T, Chen C-L. Leptin and cholesterol levels are low in major depressive disorder, but high in schizophrenia. J Affect Disord. 2006;90:21-7.

60. Lebrun B, Bariohay B, Moyse E, Jean A. Brain-derived neurotrophic factor (BDNF) and food intake regulation: a minireview. Auton Neurosci. 2006;126:30-8

61. Nabi H, Bochud M, Glaus J, Lasserre AM, Waeber G, Vollenweider P, et al. Association of serum homocysteine with major depressive disorder: results from a large population-based study. Psychoneuroendocrino. 2013;38:2309-18.

62. Wisén AG, Ekberg K, Wohlfart B, Ekman R, Westrin A. Plasma ANP and BNP during exercise in patients with major depressive disorder and in healthy controls. J Affect Disord. 2011;129:371-5.

63. Hedblad B, Nilsson P, Engström G, Berglund G, Janzon L. Insulin resistance in non-diabetic subjects is associated with increased incidence of myocardial infarction and death. Diabet Med. 2002;19:470-5.

64. Velagaleti RS, Gona P, Larson MG, Wang TJ, Levy D, Benjamin EJ, et al. Multimarker approach for the prediction of heart failure incidence in the community. Circulation. 2010;122:1700-6. doi:10.1161/ CIRCULATIONAHA.109.929661.

65. Taylor CB, Youngblood ME, Catellier D, Veith RC, Carney RM, Burg MM, et al. Effects of antidepressant medication on morbidity and mortality in depressed patients after myocardial infarction. Arch Gen Psychiatry. 2005:62:792-8

66. Cohen HW, Gibson G, Alderman MH. Excess risk of myocardial infarction in patients treated with antidepressant medications: association with use of tricyclic agents. Am J Med. 2000;108:2-8.

67. Pizzi C, Mancini S, Angeloni L, Fontana F, Manzoli L, Costa G. Effects of selective serotonin reuptake inhibitor therapy on endothelial function and inflammatory markers in patients with coronary heart disease. Clin Pharmacol Ther. 2009;86:527-32.

68. Eller T, Vasar V, Shlik J, Maron E. Pro-inflammatory cytokines and treatment response to escitaloprsam in major depressive disorder. Prog Neuropsychopharmacol Biol Psychiatry. 2008;32:445-50.

69. Gustafsson B, Thommesen L, Stunes AK, Tommeras K, Westbroek I, Waldum $\mathrm{H}$, et al. Serotonin and fluoxetine modulate bone cell function in vitro. J Cell Biochem. 2006:98:139-51.

70. Weintrob N, Cohen D, Klipper-Aurbach Y, Zadik Z, Dickerman Z. Decreased growth during therapy with selective serotonin reuptake inhibitors. Arch Pediatr Adolesc Med. 2002;156:696-701.

71. Michelson D, Amsterdam J, Apter J, Fava M, Londborg P, Tamura R, et al. Hormonal markers of stress response following interruption of selective serotonin reuptake inhibitor treatment. Psychoneuroendocrino. 2000;25:169-77.
72. Weber-Hamann B, Werner M, Hentschel F, Bindeballe $N$, Lederbogen F, Deuschle $\mathrm{M}$, et al. Metabolic changes in elderly patients with major depression: evidence for increased accumulation of visceral fat at follow-up. Psychoneuroendocrino. 2006;31:347-54.

73. Narita K, Murata T, Takahashi T, Kosaka H, Omata N, Wada Y. Plasma levels of adiponectin and tumor necrosis factor-alpha in patients with remitted major depression receiving long-term maintenance antidepressant therapy. Prog Neuropsychopharmacol Biol Psychiatry. 2006;30:1159-62.

74. Manthey L, Leeds C, Giltay EJ, van Veen T, Vreeburg SA, Penninx BW, et al. Antidepressant use and salivary cortisol in depressive and anxiety disorders. Eur Neuropsychopharmacol. 2011;21:691-9.

75. Dziurkowska E, Wesolowski M, Dziurkowski M. Salivary cortisol in women with major depressive disorder under selective serotonin reuptake inhibitors therapy. Arch Womens Ment Health. 2013;16:139-47.

76. Le Melledo J, Mailo K, Lara N, Abadia M, Gil L, Van Ameringen M, et al. Paroxetine-induced increase in LDL cholesterol levels. J Psychopharmacol. 2009;23:826-30.

77. Kim EJ, Yu B-H. Increased cholesterol levels after paroxetine treatment in patients with panic disorder. J Clin Psychopharmacol. 2005;25:597-9.

78. Ozsoy S, Besirli A, Abdulrezzak U, Basturk M. Serum ghrelin and leptin levels in patients with depression and the effects of treatment. Psychiatry Investig. 2014;11:167-72.

79. Klok M, Jakobsdottir S, Drent M. The role of leptin and ghrelin in the regulation of food intake and body weight in humans: a review. Obes Rev. 2007:8:21-34.

80. Khanzode SD, Dakhale GN, Khanzode SS, Saoji A, Palasodkar R. Oxidative damage and major depression: the potential antioxidant action of selective serotonin re-uptake inhibitors. Redox Rep. 2003;8:365-70.

81. Taniyama Y, Griendling KK. Reactive oxygen species in the vasculature molecular and cellular mechanisms. Hypertension. 2003;42:1075-81.

82. Glassman AH, O'Connor CM, Califf RM, Swedberg K, Schwartz P, Bigger Jr JT, et al. Sertraline treatment of major depression in patients with acute Ml or unstable angina. JAMA. 2002;288:701-9.

83. Tsapakis E, Gamie Z, Tran G, Adshead S, Lampard A, Mantalaris A, et al. The adverse skeletal effects of selective serotonin reuptake inhibitors. Eur Psychiatry. 2012;27:156-69.

84. Trindade E, Menon D, Topfer L-A, Coloma C. Adverse effects associated with selective serotonin reuptake inhibitors and tricyclic antidepressants: a metaanalysis. Can Med Assoc J. 1998;159:1245-52.

85. Goldberg RJ. Adverse effects of selective serotonin reuptake inhibitors. Arch Fam Med. 1999:8:196.

86. Hiemke C, Härtter S. Pharmacokinetics of selective serotonin reuptake inhibitors. Pharmacol Ther. 2000;85:11-28.

87. Mazza M, Lotrionte M, Biondi-Zoccai G, Abbate A, Sheiban I, Romagnoli E. Selective serotonin reuptake inhibitors provide significant lower re-hospitalization rates in patients recovering from acute coronary syndromes: evidence from a meta-analysis. J Psychopharmacol. 2010;24:1785-92.

88. MacGillivray S, Arroll B, Hatcher S, Ogston S, Reid I, Sullivan F, et al. Efficacy and tolerability of selective serotonin reuptake inhibitors compared with tricyclic antidepressants in depression treated in primary care: systematic review and meta-analysis. BMJ. 2003;326:1014.

89. Suwa M, Kishimoto H, Nofuji $Y$, Nakano H, Sasaki H, Radak Z, et al. Serum brain-derived neurotrophic factor level is increased and associated with obesity in newly diagnosed female patients with type 2 diabetes mellitus. Metabolism. 2006:55:852-7

90. Mclntyre RS, Soczynska JK, Konarski JZ, Woldeyohannes HO, Law CW, Miranda A, et al. Should depressive syndromes be reclassified as "metabolic syndrome type II"? Ann Clin Psychiatry. 2007;19:257-64.

91. Grenard JL, Munjas BA, Adams JL, Suttorp M, Maglione M, McGlynn EA, et al. Depression and medication adherence in the treatment of chronic diseases in the United States: a meta-analysis. J Gen Intern Med. 2011;26:1175-82.

92. Barth J, Schumacher M, Herrmann-Lingen C. Depression as a risk factor for mortality in patients with coronary heart disease: a meta-analysis. Psychosom Med. 2004;66:802-13.

93. Lichtman JH, Froelicher ES, Blumenthal JA, Carney RM, Doering LV, Frasure-Smith N, et al. Depression as a risk factor for poor prognosis among patients with acute coronary syndrome: systematic review and recommendations: a scientific statement from the American Heart Association. Circulation. 2014;129:1350-69. 
94. Lichtman JH, Bigger JT, Blumenthal JA, Frasure-Smith N, Kaufmann PG, Lespérance $F$, et al. Depression and coronary heart disease recommendations for screening, referral, and treatment: a science advisory from the American Heart Association Prevention Committee of the Council on Cardiovascular Nursing, Council on Clinical Cardiology, Council on Epidemiology and Prevention, and Interdisciplinary Council on Quality of Care and Outcomes Research: endorsed by the American Psychiatric Association. Circulation. 2008;118:1768-75.

95. Krishnan V, Nestler EJ. The molecular neurobiology of depression. Nature. 2008:455:894-902.

96. Feder A, Nestler EJ, Charney DS. Psychobiology and molecular genetics of resilience. Nat Rev Neurosci. 2009;10:446-57.

97. Ikehara S, Iso H, Toyoshima H, Date C, Yamamoto A, Kikuchi S, et al. Alcohol consumption and mortality from stroke and coronary heart disease among Japanese men and women: The Japan Collaborative Cohort study. Stroke. 2008;39:2936-42.

98. Stocker R, Keaney JF. Role of oxidative modifications in atherosclerosis. Physiol Rev. 2004;84:1381-478.

99. McEwen BS. Central effects of stress hormones in health and disease: understanding the protective and damaging effects of stress and stress mediators. Eur J Pharmacol. 2008;583:174-85.

100. Epstein FH, Ross R. Atherosclerosis-an inflammatory disease. N Engl J Med. 1999:340:115-26

101. Shai S-Y, Sukhanov S, Higashi Y, Vaughn C, Rosen CJ, Delafontaine P. Low circulating insulin-like growth factor I increases atherosclerosis in ApoE-deficient mice. Am J Physiol Heart Circ Physiol. 2011;300:H1898.

102. Ruidavets J, Luc G, Machez E, Genoux A, Kee F, Arveiler D, et al. Effects of insulin-like growth factor 1 in preventing acute coronary syndromes: The PRIME study. Atherosclerosis. 2011:218:464-9.

103. Higashi Y, Sukhanov S, Anwar A, Shai S-Y, Delafontaine P. Aging, atherosclerosis, and IGF-1. J Gerontol A Biol Sci Med Sci. 2012;67:626-39.

104. Libby P, Ridker PM, Hansson GK. Progress and challenges in translating the biology of atherosclerosis. Nature. 2011;473:317-25.

105. Mazzone T, Chait A, Plutzky J. Cardiovascular disease risk in type 2 diabetes mellitus: insights from mechanistic studies. Lancet. 2008;371:1800-9.

106. Mokuda O, Tanaka H, Hayashi T, Ooka H, Okazaki R, Sakamoto Y. Ethanol stimulates glycogenolysis and inhibits both glycogenesis via gluconeogenesis and from exogenous glucose in perfused rat liver. Ann Nutr Metab. 2004;48:276-80.

107. Siler SQ, Neese RA, Christiansen MP, Hellerstein MK. The inhibition of gluconeogenesis following alcohol in humans. Am J Physiol Endocrinol Metab. 1998;275:E897-907.

108. Krebs H, Freedland R, Hems R, Stubbs M. Inhibition of hepatic gluconeogenesis by ethanol. Biochem J. 1969;112:117-24.

109. von der Thüsen JH, Borensztajn KS, Moimas S, van Heiningen S, Teeling $P$, van Berkel TJ, et al. IGF-1 has plaque-stabilizing effects in atherosclerosis by altering vascular smooth muscle cell phenotype. Am J Pathol. 2011;178:924-34.

110. Calabrese F, Molteni R, Racagni G, Riva MA. Neuronal plasticity: a link between stress and mood disorders. Psychoneuroendocrino. 2009;34:S208-S16.

111. Myers J, Kaykha A, George S, Abella J, Zaheer N, Lear S, et al. Fitness versus physical activity patterns in predicting mortality in men. Am J Med. 2004;117:912-8.

112. Green DJ, O'Driscoll G, Joyner MJ, Cable NT. Exercise and cardiovascular risk reduction: time to update the rationale for exercise? J Appl Physiol. 2008;105:766-8

113. Jenkins NT, Martin JS, Laughlin MH, Padilla J. Exercise-induced signals for vascular endothelial adaptations: implications for cardiovascular disease. Curr Cardiovasc Risk Rep. 2012;6:331-46.

114. Høstmark AT, Ekeland GS, Beckstrøm AC, Meen HD. Postprandial light physical activity blunts the blood glucose increase. Prev Med. 2006;42:369-71.

115. Boulé NG, Weisnagel SJ, Lakka TA, Tremblay A, Bergman RN, Rankinen T, et al. Effects of exercise training on glucose homeostasis: The HERITAGE Family study. Diabetes Care. 2005;28:108-14.

116. Temelkova-Kurktschiev TS, Koehler C, Henkel E, Leonhardt W, Fuecker K, Hanefeld M. Postchallenge plasma glucose and glycemic spikes are more strongly associated with atherosclerosis than fasting glucose or $\mathrm{HbA1c}$ level. Diabetes Care. 2000;23:1830-4.

117. Okutsu M, Suzuki K, Ishijima T, Peake J, Higuchi M. The effects of acute exercise-induced cortisol on CCR2 expression on human monocytes. Brain Behav Immun. 2008:22:1066-71.
118. Golbidi S, Laher I. Exercise and the cardiovascular system. Cardiol Res Pract. 2012;2012:e210852.

119. Mougios V. Exercise biochemistry. Champaign, IL: Human Kinetics; 2006.

120. Yu Z, Ye X, Wang J, Qi Q, Franco OH, Rennie KL, et al. Associations of physical activity with inflammatory factors, adipocytokines, and metabolic syndrome in middle-aged and older chinese people. Circulation. 2009;119:2969-77.

121. Celano CM, Huffman JC. Depression and cardiac disease: a review. Cardiol Rev. 2011;19:130-42.

122. Sher $Y$, Lolak S, Maldonado JR. The impact of depression in heart disease Curr Psychiatry Rep. 2010;12:255-64

123. Wang JC, Bennett M. Aging and atherosclerosis mechanisms, functional consequences, and potential therapeutics for cellular senescence. Circ Res. 2012;111:245-59.

124. Granados-Principal S, El-Azem N, Quiles JL, Perez-Lopez P, Gonzalez A, Ramirez-Tortosa M. Relationship between cardiovascular risk factors and periodontal disease: current knowledge. In: Gasparyan AY, editor. Cardiovascular Risk Factors. Shanghai: InTech; 2012. p. 193-216.

125. Van Gaal LF, Mertens IL, Christophe E. Mechanisms linking obesity with cardiovascular disease. Nature. 2006;444:875-80.

126. Michel T, Vanhoutte PM. Cellular signaling and NO production. Pflügers Arch Eur J Physiol. 2010;459:807-16

127. Vettore M, Leao A, Monteiro Da Silva A, Quintanilha R, Lamarca G. The relationship of stress and anxiety with chronic periodontitis. J Clin Periodontol. 2003;30:394-402

\section{Submit your next manuscript to BioMed Central and take full advantage of:}

- Convenient online submission

- Thorough peer review

- No space constraints or color figure charges

- Immediate publication on acceptance

- Inclusion in PubMed, CAS, Scopus and Google Scholar

- Research which is freely available for redistribution 